\title{
Endocarditis secundaria a catéter de derivación ventrículo-atrial
}

\section{Secondary endocarditis to ventriculo-atrial shunt}

\author{
J.P. Miramontes, I. Aláez, N. Cubino, A. Romero, J.A. Martín Oterino, A. Sánchez \\ Rodríguez
}

Sr Director:

Presentamos el caso de un paciente varón de 21 años con traumatismo craneoencefálico (TCE) hacía dos años e hidrocefalia secundaria que precisó derivación peritoneal, recambiada por infección en dos ocasiones, con colocación definitiva en aurícula derecha.

Ingresó por presentar un cuadro febril desde hacía 7 días con escalofríos y dolor faríngeo. Se trató con amoxicilina-clavulánico, evolucionó con empeoramiento del estado general y del nivel de conciencia, dolor pleurítico en hemitórax derecho y disnea progresiva. En la exploración destacaba soplo de baja intensidad sobre foco tricuspídeo y disminución del murmullo vesicular en ambas bases pulmonares con crepitantes a diversos niveles.

Hemograma: Hb 10,9 gr/dl, hematocrito $32 \%$, VCM 89 fl, leucocitos $13.000 \mu \mathrm{L}$ (neutrófilos $85,6 \%$ ), plaquetas $138.900 \mu \mathrm{L}$. Bioquímica: glucosa $105 \mathrm{mg} / \mathrm{dl}$, función renal e iones normales, AST $61 \mathrm{U} / \mathrm{L}$, ALT $89 \mathrm{U} / \mathrm{L}$, PCR $>9$ $\mathrm{mg} / \mathrm{dl}$. Estudio de coagulación normal. Gasometría: PH 7,47, PCO2 35, PO2 65, Sat O2 94\%, HCO3 25. Líquido cefalorraquídeo (LCR): células: $1 / \mathrm{mm} 3$, proteínas $31 / \mathrm{dl}$, glucosa $63 \mathrm{mg} /$

An. Sist. Sanit. Navar. 2010; 33 (1): 93-95

Servicio de Medicina Interna. Hospital Virgen de la Vega. Salamanca dl. Radiografía de tórax: sin cardiomegalia ni signos de hipertensión venocapilar, infiltrado alveolar parcheado bilateral. Ecocardiograma: grandes verrugas de endocarditis en los velos tricuspídeos, alguna de más de $2 \mathrm{~cm}$ de longitud, con insuficiencia tricuspídea ligera y presión pulmonar sistólica de 36 $\mathrm{mmHg}$, derrame pericárdico leve y fracción de eyección 53\%. Previa toma de hemocultivos y cultivo de LCR, se inició tratamiento con vancomicina intravenosa e intratecal y gentamicina y se procedió a la retirada de la válvula y del catéter a las $48 \mathrm{~h}$. A los 4 días de iniciado el tratamiento se añadió rifampicina dada la persistencia de la fiebre $\left(38,6^{\circ} \mathrm{C}\right.$ de media en picos) y la mala evolución. Posteriormente se observó crecimiento de los infiltrados pulmonares con cavitación, se confirmó con una tomografía computadorizada. Los hemocultivos confirmaron Estafilococo aureus meticilin resistente (SARM), sensible a vancomicina. A los 6 días del inicio del tratamiento planteamos el cambio a meropenem y linezolid, planteándose la posibilidad de cirugía aunque finalmente no fue necesaria, comprobándose en ecocardiografías posteriores la desaparición completa de las verrugas y la ausencia de lesión valvular residual.

\section{Correspondencia}

José Pablo Miramontes González

Hospital Virgen de la Vega

Servicio de Medicina Interna

Paseo de San Vicente $n^{\circ}$ 58-182

37007 Salamanca

E-mail: jpmiramontes@hotmail.com 


\section{DISCUSIÓN}

Las derivaciones de drenaje de LCR pueden ser externas, para uso temporal, e internas, para uso permanente, que se dividen en tipos según la localización del catéter a nivel distal: sonda ventrículo-peritoneal (SVP), la más usada en hidrocefalias obstructivas, sonda ventrículo-atrial (SVA), para casos en los que la SVP esté contraindicada y ventrículo-pleural, de uso muy limitado. Una de las principales complica- ciones de estos catéteres son las infecciones, representando la mitad de las meningitis nosocomiales en adultos ${ }^{1,2}$. En las SVA, la incidencia de infección oscila entre 4,2 y $6,2 \%{ }^{3}$. Los factores de riesgo son: edad avanzada, manipulación del catéter, infecciones previas del sistema, cirugía previa, tiempo prolongado del acto quirúrgico, e incluso, el contacto con la válvula tricúspide. Existen cuatro mecanismos que favorecen la infección ${ }^{4}$ :

Figura 1. Imagen de ecocardioagrafía transtorácica que muestra verrugas valvulares.

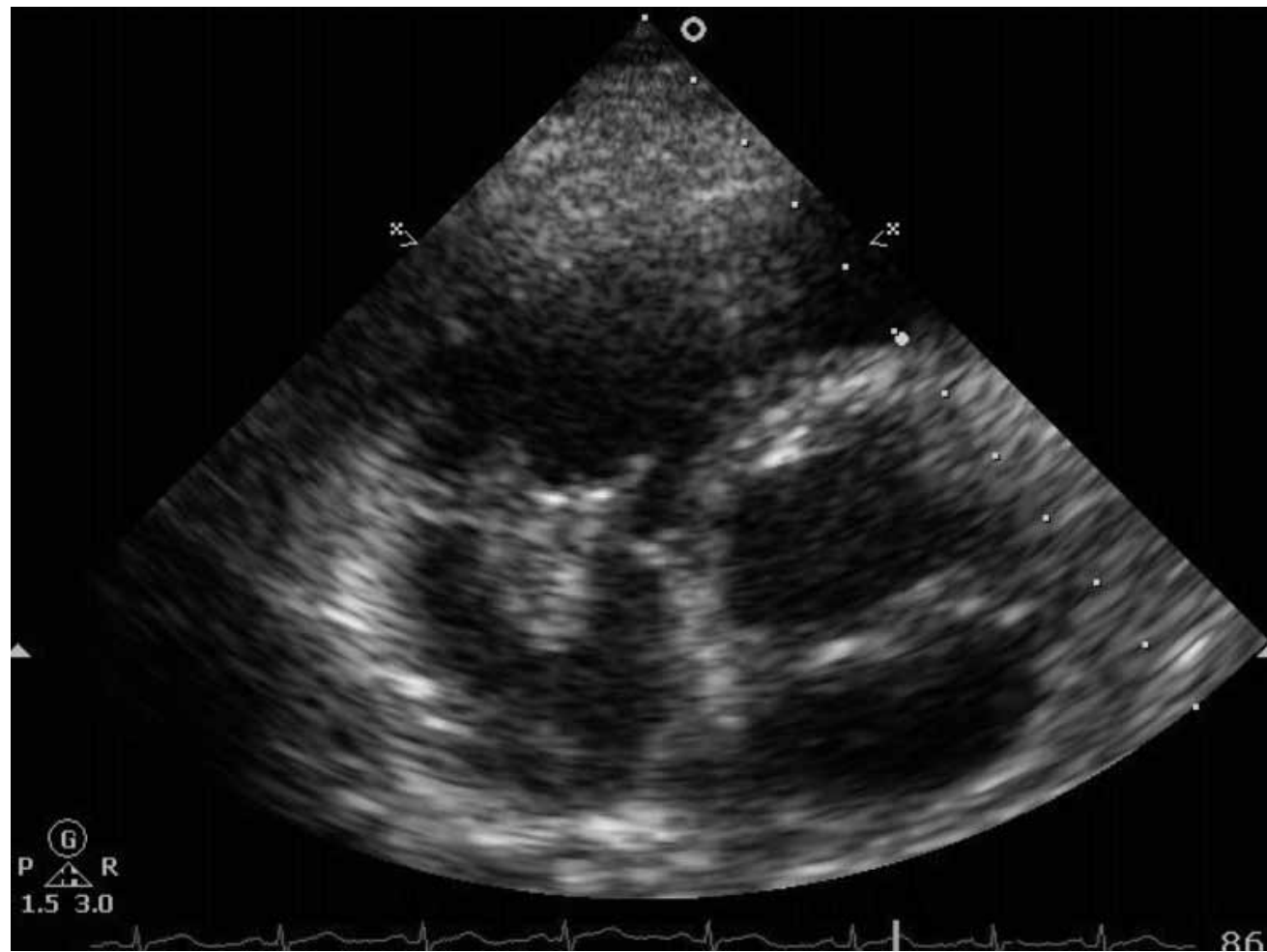

1. Derivados de la cirugía son los más frecuentes; la infección aparece a las pocas semanas y la flora habitual es saprofita de la piel o nasofaringe.

2. Por contigüidad de la piel al catéter, la herida quirúrgica y manipulación para extracción de LCR: las bacterias son similares a las del primer caso.
3. Contaminación vía hematógena por bacteriemias: de aparición más tardía, es el más frecuente en el SVA; en las SVP, las infecciones pueden ser por contaminación tras perforación intestinal.

4. Infección retrógrada del catéter: más frecuente en derivaciones externas. 
Los microorganismos aislados con mayor frecuencia son Staphylococcus epidermidis y aureus (60-80\%), de los cuales la mitad son meticilín resistentes ${ }^{5}$; bacilos gram negativos (10-25\%) como Eschericha coli, Enterobacter spp, Klebsiella pneumoniae y Pseudomonas aeruginosa ${ }^{3}$; e infección polimicrobiana (10\%) por anaerobios y enterobacterias en SVP tras perforación intestinal $^{5}$. Los síntomas principales son la cefalea y la alteración del nivel de conciencia $(20-70 \%)^{6}$. Las crisis comiciales, defectos campimétricos y signos meníngeos son poco frecuentes. Las complicaciones cardiacas más habituales son la insuficiencia cardíaca y las propiamente valvulares pudiendo llegar al recambio quirúrgico.

En la infección asociada a SVA la fiebre es casi constante, presentándose como sepsis, endocarditis tricuspídea o émbolos sépticos pulmonares. La nefritis es infrecuente y casi exclusiva de estas infecciones por depósito de complejos Ig M e Ig G con activación del complemento ${ }^{7}$. En nuestro caso, destacamos la ausencia de insuficiencia cardiaca, siendo toda la sintomatología secundaria los embolismos pulmonares dado el considerable tamaño de las verrugas. En el diagnóstico es fundamental la sospecha clínica para iniciar cuanto antes el tratamiento antibiótico precozmente y retirar el catéter, ya que sí éste se mantiene sólo alcanza curación el 24-33,5\% de los casos. Para retirarlo deben pasar, al menos, 10 días con antibióticos desde el último hemocultivo positivo, obteniéndose curación en el $87 \%^{8}$ de casos. De forma empírica, se recomienda la vancomicina asociada con aminoglucósido y rifampicina por la presencia de material protésico ${ }^{9,10}$. Como alternativa a la vancomicina está el linezolid o la daptomicina, con mejor penetrancia a nivel SNC ${ }^{11}$.

\section{BIBLIOGRAFÍA}

1. Weisfelt M, Van der Beek D, SpanjaArd L, de Gans J. Nosocomial bacterial meningitis in adults: a prospective series of 50 cases. J Hosp Infect 2007; 66: 71-78.

2. Wang KW, Chang WN, Huang CR, Tsai NW, Tsui HW, WANG HC et al. Post-surgical nosocomial bacterial meningitis in adults: microbiology, clinicalfeatures, and outcomes. J Clin Neurosci $2005 ; 12$ : 647-650.

3. National Nosocomial Infections Surveillance (NNSI) System Report, data summary from January 1992 to June 2002. Am J Infect Control 2002; 30: 458-475.

4. JimÉnez-Mejías ME, García-Cabrera E. Infecciones relacionadas con lossistemas de drenaje de líquido cefalorraquídeo. Enferm Infecc Microbiol Clin 2008; 26: 240-251.

5. Wang KW, Chang WN, ShiH TY, Huang CR, Tsai NW, CHANG CS et al.Infection of cerebrospinal fluid shunts: causative pathogens, clinical features, and outcomes. Jpn J Infect Dis 2004; 57: 44-48.

6. Conen A, Walti ln, Merlo A, Fluckiger U, BAttegay M, Trampuz A. Characteristics and tratament outcome of cerebroespinal fluid shunt-associated infections in adults: a retrospective analysis over an 11-year period. Clin Infect Dis 2008; 47: 73-82.

7. Samtleben W, Bosch T, Bauriedel G, Götz C, KlaRE B, Henselmann L et al. Internal medicine complications of ventriculoatrial shunt. Med Klin (Munich) 1995; 90: 67-71.

8. SCHReffler RT, SchrefFler AJ, Wittler RR. Treatment of cerebrospinal fluid shunt infections: a decision analysis. Pediatr Infect Dis J 2002; 21: 632-636.

9. BAyston R. Epidemiology, diagnosis, treatment and prevention of cerebrospinal fluid shunt infections. Neurosurg Clin North Am 2001; 36: 703-708.

10. Úriz J, Salvador B, Gutiérrez A, Petti A, Anguiano P, SAMPÉRIZ A. Vigilancia y control de las bacteriemias asociadas a dispositivos intravasculares. An Sist Sanit Navar 2000; 23 (Supl 2): 161-167.

11. Mensa J, Gatell JM, Azanza JR, Domínguez Gil A. Guía terapéutica antimicrobiana. $18^{\mathrm{a}}$ edición. Elsevier Masson. 
